\title{
Bacterial community in cold and alkaline environments of Hoh Xil basin in Qinghai-Tibet Plateau and isolation of potential sources of microbiota
}

\author{
Rui Xing ${ }^{1,2}(\mathbb{D}) \cdot$ Qing-bo Gao $^{1} \cdot$ Fa-qi Zhang ${ }^{1} \cdot$ Jiu-li Wang ${ }^{1} \cdot$ Shi-long Chen ${ }^{1}$
}

Received: 6 September 2018 / Accepted: 5 February 2019 / Published online: 16 March 2019

(C) Università degli studi di Milano 2019

\begin{abstract}
The Hoh Xil basin is the largest Cenozoic sedimentary basin in the Qinghai-Tibet Plateau (QTP) with an average altitude of above $5000 \mathrm{~m}$. It is also the coldest region in the QTP. However, due to the difficulty of sample collection caused by the harsh natural environment, a limited number of studies have been conducted on soil microorganisms in this region. We used culturedependent and independent methods to investigate the bacterial communities in desert soil (n1), saline-alkali land (n2), salinealkali wetland (n3), and soda lake sediment (n4). The results showed distinct bacterial communities between different environmental types. We found that the Chao1 and Shannon diversity indices of $\mathrm{n} 1$ were significantly lower than those of $n 4(P<0.05)$. At the phylum level, all samples were dominated by representatives of Proteobacteria, Bacteroidetes, and Actinobacteria, which were similar to the findings of previous studies on the desert soil in the same region. Moreover, we identified 10 strains of bacteria from 109 isolates, most of which belonged to Pseudomonas (90.8\%). The growth of the isolate $k 9$ was optimal at a high $\mathrm{pH}$ value $(\mathrm{pH} 10.0)$ and a low temperature $\left(5^{\circ} \mathrm{C}\right)$, and this stain could produce extracellular enzyme (alkaline phosphatase, acid phosphatase, and naphthol-AS-BI-phosphohydrolase) under alkaline $(\mathrm{pH} 10)$ and cold $\left(5^{\circ} \mathrm{C}\right)$ condition. These results demonstrate the diversity of bacteria in the Hoh Xil basin and identify potential psychrophilic and alkaliphilic bacteria with multiple types of extracellular enzyme activity.
\end{abstract}

Keywords Qinghai-Tibet Plateau · Alkaliphiles bacteria $\cdot$ Psychrophilic bacteria $\cdot$ Psychrotolerant alkaliphile $\cdot$ Microbial community

Electronic supplementary material The online version of this article (https://doi.org/10.1007/s13213-019-01447-w) contains supplementary material, which is available to authorized users.

Shi-long Chen

slchen@nwipb.cas.cn

Rui Xing

xingrui@nwipb.cas.cn

Qing-bo Gao

qbgao@nwipb.cas.cn

Fa-qi Zhang

fqzhang@nwipb.cas.cn

Jiu-li Wang

983117404@qq.com

1 Key Laboratory of Adaptation and Evolution of Plateau Biota, Northwest Institute of Plateau Biology, Chinese Academy of Sciences, 59 Xiguan Avenue, Xining 810001, Qinghai, People's Republic of China

2 Qinghai Provincial Key Laboratory of Crop Molecular Breeding, Xining, China

\section{Introduction}

The Qinghai-Tibet Plateau (QTP) is the highest and most extensive plateau on our planet. It is well known as the "roof" of the world and the "third pole" of the Earth due to its high elevation and cold environment (Tang and Shen 1996). The Hoh Xil basin, located on the platform of the QTP, has been listed among the World Heritage Sites as "the largest and highest plateau in the world," with an area of $101,000 \mathrm{~km}^{2}$ and an average elevation of over $5000 \mathrm{~m}$. It is the largest Cenozoic sedimentary basin in the hinterland of the Tibetan Plateau with a large area of salinealkali land (Wen et al. 2007). This area is one of the coldest regions on the QTP, with an average temperature in January of below $-30{ }^{\circ} \mathrm{C}$ and average temperatures only in July and August of above $0{ }^{\circ} \mathrm{C}$ (Liu et al. 2014). This region contains a wide variety of algae and animals, many of which are unique. Nevertheless, it has received much 
less attention than it deserves because of its harsh conditions for fieldwork.

The extreme alkaline, acidic, and extremely cold environments represent a great microbial resource. A growing body of evidence has shown the advantages of using enzymes derived from psychrophilic microorganisms which live in cold environments, such as the depths of oceans, the high-altitude regions, and the polar regions (Feller 2013; Struvay and Feller 2012). The cold-active biocatalyst compounds produced by these microorganisms have a more flexible structure, which enables their high specificity of action at low temperatures. Certain industrial applications use such enzymes to save energy, improve hygiene, and reduce the risk of contamination (Cavicchioli et al. (2011). Meanwhile, the enzymes active at high $\mathrm{pH}$ that are produced by alkaliphiles are also of industrial interest, focused in fields, such as waste management and the textile and detergent industries. In the detergent industry, alkaline proteases, amylases, cellulases, and lipases are all widely used in detergent formulations (Fujinami and Fujisawa 2010; Horikoshi 1999). Thus, the isolation of psychrophilic and alkaliphile bacteria from cold and alkaline environments is required for the discovery and isolation of cold- and alkaline-active enzymes with industrial potential. How even, most of the natural, stable alkaline environments, such as soda lakes and soda deserts, are located mainly in the temperate areas of Africa and Central Asia. Thus, the alkaliphilic bacteria isolated from soils of these regions are predominantly meso- or thermophilic. Nevertheless, isolation of psychrophilic and alkaliphilic bacteria from natural environments has been rarely reported (Duckworth et al. 1996; Zhilina and Zavarzin 1994).

Due to the difficulty in collecting samples in the harsh natural environment of Hoh Xil, only a few studies have been performed on soil microorganisms in this region. For example, Sun et al. (2011) isolated five strains of bacteria from the saline-alkali soil in Hoh Xil and found that the Geomicrobium halophilum strain CPCC100153 had an optimal growth at a temperature of $28{ }^{\circ} \mathrm{C}$ and $\mathrm{pH}$ of 8.0-9.5. Extracellular enzymes produced by this strain, such as phosphatase and esterase, were identified to possess industrial potential (Sun et al. 2011). In addition, Su et al. (2011) used culture-dependent and culture-independent (PCR-DGGE) methods to investigate the bacterial communities in a soil sample from Hoh Xil and found that $\beta$-Proteobacteria was the dominant phylum $(75.0 \%)$ in the sample studied $(\mathrm{Su}$ et al. 2011). In another investigation, Wang et al. (2017) isolated 66 strains of the Bacillus species in soil samples from Hoh Xil and discovered two potential new species of alkaliphilic Bacillus with 16S rRNA gene similarities of $97.00 \%$ and $98.65 \%$ (Wang et al. 2017).

It is considered that only a small number of bacteria can be cultured in the laboratory. Previous work on soil bacteria mainly focused on isolate cultures. Therefore, to comprehensively investigate the structure, diversity, and abundance of soil bacteria in soil samples from the soda desert, saline-alkali land, saline-alkali wetland, and soda lake sediment in the Hoh Xil basin of the QTP, we employed a combination of culture-dependent and culture-independent (Illumina sequencing) methods to identify and characterize psychrophilic and alkali-tolerant bacteria with industrial potential from this unique environment.

\section{Material and methods}

\section{Soil sampling}

We collected a total of 20 soil samples from the desert (n1), saline-alkali land (n2), saline-alkali wetland (n3), and soda lake sediment (n4) (50 cm depth) in the Hoh Xil from July to August 2015 (Fig. S1; Table S1). The samples were collected from five sites in each of the environments examined. More specifically, the upper 15-cm layer of soil was collected from five random locations within a given plot of $100 \mathrm{~m}^{2}$ and composited into a single soil sample. All soil samples were placed for storage at $4{ }^{\circ} \mathrm{C}$ and immediately transported to the Key Laboratory of Adaptation and Evolution of Plateau Biota, Chinese Academy of Sciences, Qinghai, China, where they were stored at $-20{ }^{\circ} \mathrm{C}$ until processing. Soil analyses were performed for determination of total C (TC), total $\mathrm{N}(\mathrm{TN})$, and $\mathrm{C}: \mathrm{N}$ ratio. Initially, the soil was air-dried, then sieved (using a 2-mm mesh), followed by removal of fine roots, ground. Further, the samples were subjected to combustion analysis using the LECO CNS-2000 elemental analyzer (LECO, St. Joseph, MI, USA). Soil total phosphorus was extracted with double acid $\left(0.025 \mathrm{NH}_{2} \mathrm{SO}_{4}\right.$ and $\left.0.05 \mathrm{~N} \mathrm{HCl}\right)$ and analyzed using an inductively coupled spectrophotometer Shimadzu RF-5301PC (Shimadzu Institute, University of Texas at

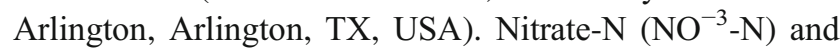
ammonium- $\mathrm{N}\left(\mathrm{NH}^{+4}-\mathrm{N}\right)$ were extracted in $2 \mathrm{M} \mathrm{KCl}$, and their concentrations were measured using Scalar SANplus segmented flow analyzer (Scalar SANplus segmented flow analyzer, Scalar SANplus, Skalar, the Netherlands). Total soil pH was determined in a fresh soil to water ratio of 1:5 by Leici PHS-3c pH meter (Shanghai Leici Corporation, Shanghai, China), and the soil conductivity was measured using Leici DDS-307A conductivity meter (Shanghai Leici Corporation, Shanghai, China). Mean annual temperature (MAT) was compiled from the WorldClim database (www.worldclim.org) at 30 arc sec resolution.

\section{DNA extraction and HiSeq sequencing}

Total DNA from each sample was extracted under sterile conditions from $0.5 \mathrm{~g}$ of soil by using a FastDNA ${ }^{\circledR}$ Spin kit (MoBio, Carlsbad, CA, USA) according to the manufacturer's 
instructions and stored at $-20{ }^{\circ} \mathrm{C}$. The DNA samples were then frozen-transported to the laboratory of Novogene Bioinformatics Technology Co., Ltd., Beijing, China, and analyzed using the Illumina HiSeq platform and the primers 515F (5'- GTG CCA GCM GCC GCG GTA A)/806R (5'GGA CTA CHV GGG TWT CTA AT) (Caporaso et al. 2011). The thermal cycling conditions consisted of initial denaturation at $95^{\circ} \mathrm{C}$ for $3 \mathrm{~min}$, followed by 30 cycles of denaturation at $95{ }^{\circ} \mathrm{C}$ for $30 \mathrm{~s}$, annealing at $50{ }^{\circ} \mathrm{C}$ for $30 \mathrm{~s}$, and elongation at $72{ }^{\circ} \mathrm{C}$ for $60 \mathrm{~s}$, and finally, the cycling was completed at $72{ }^{\circ} \mathrm{C}$ for $7 \mathrm{~min}$. A sequencing library was generated using the KAPA Library Preparation Kit (Kapa, MA, USA) following the manufacturer's instructions and quantified by an Agilent Bioanalyzer 2100 system (Agilent Technologies, San Diego, CA, USA). Finally, the quantified library was sequenced on a HiSeq2500 platform (Illumina, CA, USA), and $2 \times 250$ base pairs (PE250) were generated.

\section{Data analysis}

Paired-end reads from the original DNA fragments were merged using FLASH V1.2.7 (Mago and Salzberg 2011). Raw sequence data were processed and analyzed using the quantitative insight into microbial ecology (QIIME) pipeline (http://qiime.sourceforge.net/) (Caporaso et al. 2010). Reads with a length of $<200 \mathrm{bp}$ or with an average quality score of $<$ 25 were removed (Huse et al. 2007). Clustering of quality sequences into operational taxonomic units (OTUs) was performed through UCLUST at a similarity level of 97\% (Edgar 2010). The taxonomy of the generated OTUs was analyzed by RDP Classifier (Wang et al. 2013) against the Silva rRNA gene database (https://www.arb-silva.de/) with a confidence threshold of $80 \%$. All samples were normalized at the same sequence depth, and the OTUs were used to calculate alphadiversity indices (Chao1, Shannon, and Simpson) by using inhouse Perl Scripts. Beta-diversity indices between samples were determined based on weighted and unweighted UniFrac distance matrices (Lozupone and Knight 2005), which were also applied for principal coordinates analysis (PCoA). A two-dimensional plane determined by PCoA was used to determine whether communities with similar characteristics tended to cluster together. The microbial community data were subjected to non-metric multidimensional scaling analyses (NMDS) using the Bray-Curtis dissimilarity matrix in the vegan package (Dixon 2003) R364 3.0.1(http://cran. stat.sfu.ca/). The comparison of relative abundances of microbes between different zones was performed in STAMP software (Parks et al. 2014), using the data generated by QIIME's taxonomy assignment. STAMP calculated diversity differences between samples based on the analysis of variances (ANOVA) with a significant level of $P<0.05$, and significant differences between groups of samples were investigated using Tukey-Kramer's post hoc test. Canonical correspondence analysis (CCA) was performed to evaluate the chemical properties that had the most significant influence on the microbial community structure. The significant correlations of the physiochemical parameters were examined by the vegan package (Dixon 2003) R364 3.0.1 (http://cran.stat. sfu.ca/).

Sequences generated in this study have been deposited in the National Center for Biotechnology information (NCBI) database under accession number PRJNA480132 (https:// www.ncbi.nlm.nih.gov/bioproject/PRJNA480132).

\section{Isolation and characteristics of psychrophilic and alkaliphilic bacteria}

The soil samples ( $1 \mathrm{~g}$ fresh weight) were suspended in $9 \mathrm{~mL}$ sterile water under shaking for $15 \mathrm{~min}$. Bacterial suspension $(1 \mathrm{~mL})$ was transferred into a tube with $9 \mathrm{~mL}$ of sterile water. Serial dilutions were made, and $0.1 \mathrm{~mL}$ aliquots $\left(10^{-2}-10^{-6}\right)$ of homogenized suspensions were spread on a Petri dish containing R2A agar (pH 7.0) and cultured at $5{ }^{\circ} \mathrm{C} .16 \mathrm{~S}$ rDNA sequencing was used for identification of all the isolates. The 16S rDNA amplification was carried out by colony PCR reaction, using 27F (AGA GTT TGA TCM TGG CTC AG) and 1492R (TAC GGY TAC CTT GTT ACG AC TT) primers (Stackebrandt and Goodfellow 1991). PCR was performed in $15 \mu \mathrm{L}$ of a solution containing $20 \mathrm{ng}$ of genomic DNA, $200 \mathrm{mM} 10 \times$ PCR buffer, $1.5 \mathrm{mM} \mathrm{MgCl} 2,0.2 \mathrm{mM}$ dNTPs, $200 \mathrm{nM}$ of each primer, and $1 \mathrm{U}$ of Taq DNA polymerase (Takara, Dalian, China). The following PCR program was used: initial denaturation for $5 \mathrm{~min}$ at $95{ }^{\circ} \mathrm{C}, 35$ cycles of $30 \mathrm{~s}$ each at $95^{\circ} \mathrm{C}, 57^{\circ} \mathrm{C}$ for $90 \mathrm{~s}, 40 \mathrm{~s}$ at $72{ }^{\circ} \mathrm{C}$, and a final extension for $10 \mathrm{~min}$ at $72^{\circ} \mathrm{C}$. The PCR products were detected using $1 \%$ agarose gels run at $100 \mathrm{~V}$ for $20 \mathrm{~min}$ and visualized under UV light. After purification by the PCR product purification kit (Qiagen), following the recommended protocol, the PCR products were sequenced using an ABI 3730 automated sequencer (Beijing Sunbiotech, Biotech Co., Ltd.). The sequences were then compared to available bacterial sequences in GenBank using the BLAST program in the National Center for Biotechnology Information (http://blast. ncbi.nlm.nih.gov/Blast.cgi).

\section{Determination of temperature, pH optimum, and extracellular enzymatic activity}

The R2A solid medium was adjusted to various $\mathrm{pH}$ values, $\mathrm{pH} 10.0$ (addition of $100 \mathrm{~mL}$ of $1 \mathrm{M} \mathrm{Na}_{2} \mathrm{CO}_{3}$ ), pH 9.0 (addition of $100 \mathrm{~mL} 1 \mathrm{M} \mathrm{NaHCO}_{3}$ ), pH 8.0 (addition of $100 \mathrm{~mL}$ of $1.0 \mathrm{M} \mathrm{NaHPO}_{4}$ ), $\mathrm{pH} 7.0$ (addition of $100 \mathrm{~mL}$ of $1.0 \mathrm{M}$ sodium phosphate buffer), and $\mathrm{pH} 6.0$ (adjusted with $\mathrm{HCl}$ ), and the signal isolates were incubated at $15^{\circ} \mathrm{C}$ on each medium. The $\mathrm{pH}$ was also measured at the end of the incubation. The growth performance of the individual colonies was interpreted 
on a scale from "-_" (no growth) to " $++"$ (good growth). The $\mathrm{pH}$ was measured at the end of the incubation. To determine the optimum temperature of the individual strains, the R2A medium was adjusted to the optimal $\mathrm{pH}$ and incubated at $5^{\circ} \mathrm{C}$, $10{ }^{\circ} \mathrm{C}, 15^{\circ} \mathrm{C}, 20{ }^{\circ} \mathrm{C}, 30{ }^{\circ} \mathrm{C}$, and $37{ }^{\circ} \mathrm{C}$. The growth was measured using a scale from "-_" (no growth) to "+ +" (good growth) as described above. Extracellular enzyme activity (alkaline and acid phosphatases, butyrate esterase, caprylate esterase lipase, myristate lipase, leucine, valine and cystine aminopeptidases, trypsin, chymotrypsin, phosphoamidase, $\alpha$-galactosidase, $\beta$-galactosidase, $\beta$-glucuronidase, $\alpha$-glucosidase, $\beta$-glucosidase, $\beta$-glucosaminidase, $\alpha$-mannosidase, and $\alpha$ fucosidase) was assessed using the API ZYM kit (bioMérieux) according to the manufacturer's instructions. In addition, the extracellular enzyme activity of selected psychrotolerant alkaliphiles was also detected under $5{ }^{\circ} \mathrm{C}$ and $\mathrm{pH} 10$.

\section{Phylogenetic analysis}

The phylogenetic relationships of the strains were deduced from their 16S rRNA gene sequences. The sequences showing
Fig. 1 Taxonomic classification (phylum (a) and family (b)) of bacterial reads retrieved from four environment types in Hoh Xil by 16S rRNA Illumina sequencing. $\mathrm{n} 1$ desert soil, $\mathrm{n} 2$ saline-alkali land, $\mathrm{n} 3$ saline-alkali wetland, $\mathrm{n} 4$ soda lake sediment
Top taxonomy distribution at Phylum level n1

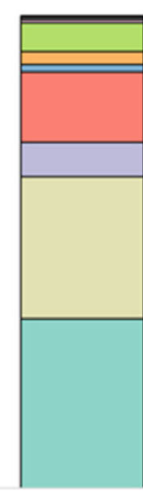

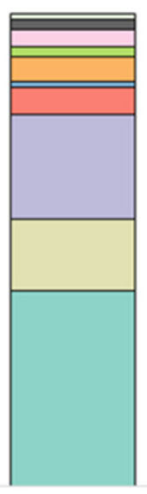

n2

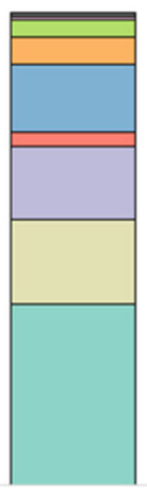

n3

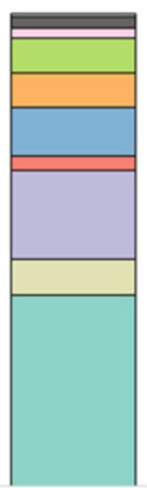

n4

$\begin{array}{lll}\square \text { Proteobacteria } & \square \text { Bacteroidetes } & \square \text { Actinobacteria } \\ \square \text { Gemmatimonadetes } & \square \text { Firmicutes } & \square \text { Chloroflexi } \\ \square \text { Acidobacteria } & \square \text { Cyanobacteria } & \square \text { Verrucomicrobia }\end{array}$

$\square$ Crenarchaeota

b Top taxonomy distribution at Family level

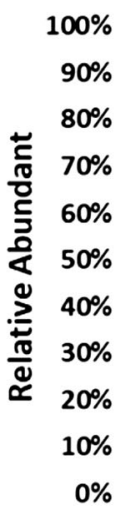

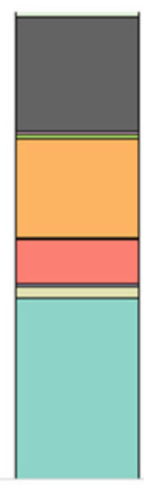

n1

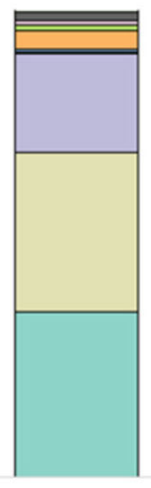

n2

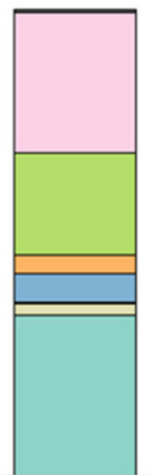

n3

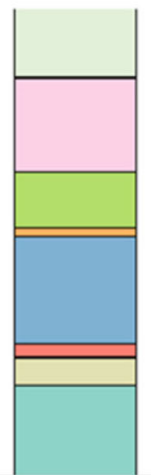

n4 $\square$ Flavobacteriaceae

$\square$ Erythrobacteraceae $\square$ Rubrobacteraceae

$\square$ Bacteroidaceae

$\square$ Bacillaceae

$\square$ Marinicellaceae

$\square$ Micrococcaceae

$\square$ Planococcaceae

Balneolaceae

$\square$ Lachnospiraceae 
the highest degree of similarity were imported into the ClustalX V2.0 software (Jeanmougin et al. 1998) and then corrected manually using the Bioedit software V5.0 (Hall 1999). A phylogenetic dendrogram was then generated based on the 16S rRNA gene sequences using the neighbor-joining method in MEGA X software package (Kumar et al. 2018).

\section{Results}

The electrical conductivity and $\mathrm{pH}$ of the soil samples used in the present study were $81.1-902 \mu \mathrm{s} / \mathrm{cm}$ and $7.02-8.91$, respectively. The values of TC, TN, and TP ranged within $7.74-23.70 \mathrm{~g} / \mathrm{kg}, 0.22-1.70 \mathrm{~g} / \mathrm{kg}$, and $0.19-0.65 \mathrm{~g} / \mathrm{kg}$, correspondingly. The mean values of the content of $\mathrm{NO}^{-3}-\mathrm{N}$ and $\mathrm{NH}^{+4}-\mathrm{N}$ were $3.26 \mathrm{~g} / \mathrm{kg}$ and $12.65 \mathrm{~g} / \mathrm{kg}$ in $\mathrm{n} 1 ; 3.36 \mathrm{~g} / \mathrm{kg}$ and $4.09 \mathrm{~g} / \mathrm{kg}$ in $\mathrm{n} 2 ; 3.03 \mathrm{~g} / \mathrm{kg}$ and $6.31 \mathrm{~g} / \mathrm{kg}$ in $\mathrm{n} 3$; and $3.49 \mathrm{~g} / \mathrm{kg}$ and $1050 \mathrm{~g} / \mathrm{kg}$ in $\mathrm{n} 4$ (Table S2).

Twenty samples obtained from four different environmental types of Hoh Xil basin were analyzed. A total of 1,110,373 reads (55,518 per sample) were obtained from the $16 \mathrm{~S}$ rRNA sequencing. From these data, we annotated 8510 operational taxonomic units (OTUs: $97 \%$ identity) which were assigned to a total of 23 bacterial phyla, including Proteobacteria (36.9\%), Bacteroidetes (16.9\%), Actinobacteria (15.1\%), and Firmicutes $(6.4 \%)$. A total of $59.9 \%$ of the sequences were assigned to 238 known bacterial families and $88.57 \%$ to 412 known bacterial genera.

The different soil samples had distinct bacterial community compositions. At the phylum level, all samples were dominated by Proteobacteria and Bacteroidetes (Fig. 1a), and the abundance of Actinobacteria in $\mathrm{n} 1$ was significantly lower than that in $\mathrm{n} 2$ and $\mathrm{n} 4$ (Figs. S2 and S3). Alphaproteobacteria and Gammaproteobacteria were the most abundant classes in all the samples, but the bacterial community structures at the class level in $\mathrm{n} 3$ and $\mathrm{n} 4$ showed heterogeneity. A total of 162 microbial orders and 190 families were detected in all the samples. Gammaproteobacteria was the predominant bacterial order in the $\mathrm{n} 1$ and $\mathrm{n} 3$, whereas Alphaproteobacteria was the predominant bacterial order in $\mathrm{n} 2$ and $\mathrm{n} 4$ (data not shown). The abundance of Actinomycetales in $\mathrm{n} 1$ was significantly lower than that in the other soil samples (Figs. S4, S5, and S6). The most abundant family in $\mathrm{n} 1(9.14 \%), \mathrm{n} 2(6.64 \%)$, and $\mathrm{n} 3(8.11 \%)$ was Flavobacteriaceae (Fig. 1b). In addition, heterogeneous bacterial community structure was observed in $\mathrm{n} 4$ at the family level. At the genus level, Bacillus and Psychrobacter were the most abundant in the $\mathrm{n} 3$ and $\mathrm{n} 4$ samples. The core microbiota (family) accounted for $84.8,86.8,76.2$, and $77.5 \%$ of the total sequences in the $\mathrm{n} 1, \mathrm{n} 2, \mathrm{n} 3$, and $\mathrm{n} 4$ samples, respectively (Fig. 2).

The average taxonomic richness (Chao1) estimated for the $16 \mathrm{~S}$ rRNA libraries of $\mathrm{n} 1, \mathrm{n} 2, \mathrm{n} 3$, and $\mathrm{n} 4$ was 2322.63 ,

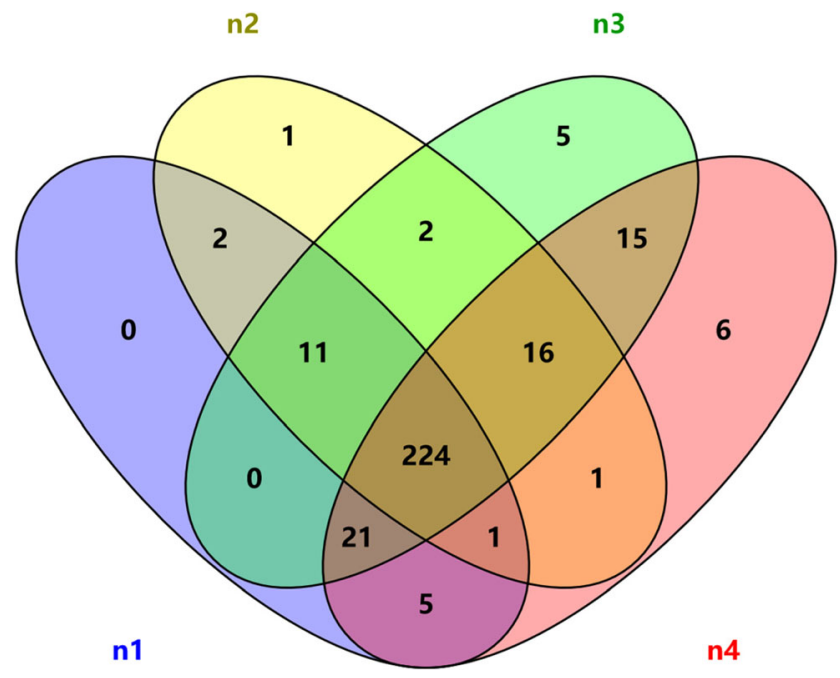

Fig. 2 Sharing of core microbiota families of four environment types. $\mathrm{n} 1$ desert soil, $\mathrm{n} 2$ saline-alkali land, $\mathrm{n} 3$ saline-alkali wetland, $\mathrm{n} 4$ soda lake sediment

2547.56, 3394.214, and 3617.96, respectively; the bacterial richness of $\mathrm{n} 1$ was significantly lower than that of $\mathrm{n} 4$ $(P<0.05)$ (Fig. 3a). The Shannon diversity index $(\mathrm{H})$ ranged from $7.75(\mathrm{n} 1)$ to $9.16(\mathrm{n} 4)$; this index in $\mathrm{n} 1$ was also significantly lower than that in $\mathrm{n} 4(P<0.05)$ (Fig. 3b). Microbial community $\beta$-diversity of $\mathrm{n} 1$ clustered separately from the other sample locations (except for one sample of n3) based on the weighted UniFrac distances, and an overlap in the distribution was observed among n2, n3, and n4 (Fig. 4a). Meanwhile, the non-metric multidimensional scaling (NMDS) showed a clear differentiation in bacterial communities among all the soil samples (Fig. 4b).

In the present study, a total of 109 bacterial strains were isolated and identified to belong to 10 species. Pseudomonas included 99 strains, accounting for $90.8 \%$ of the total isolates. Psychrobacter was identified in 16 isolates (14.7\%), and there were only two isolates with Acinetobacter, one with Hafnia, and one with Exiguobacterium (Table 1). The $\mathrm{pH}$ values of n2, $\mathrm{n} 3$, and $\mathrm{n} 4$ ranged from 7.02 to 8.91 ; thus, alkaliphilic bacteria with a growth optimum at $\mathrm{pH} 8-9$ were expected to be isolated. The isolates $k 7$ and $k 9$ displayed optimal growth at high $\mathrm{pH}$ (pH 9-10), six isolates $(k 1, k 4, k 5, k 6, k 8$, and $k 10)$ had their $\mathrm{pH}$ optimum within 7.0-9.0, and the isolates $k 2$ and $k 3$ exhibited their optimal growth at $\mathrm{pH} 8.0$ and 9.0, respectively (Table 2). To determine the temperature optimum of the cultured isolates, the bacteria were plated on R2A medium buffered to the $\mathrm{pH}$ where their growth was optimal and cultured under different temperatures (ranging within $5-37{ }^{\circ} \mathrm{C}$ ). We found that all isolates were able to grow at low temperatures $\left(5^{\circ} \mathrm{C}\right)$. However, optimal growth temperatures for most isolates were between 10 and $20^{\circ} \mathrm{C}$. Moreover, the isolates $k 2$ and $k 9$ did not grow at $37{ }^{\circ} \mathrm{C}$ (Table 2). The isolates and related reference strains were used to construct a phylogenetic tree (Fig. 5), which was composed mainly of four clusters. 

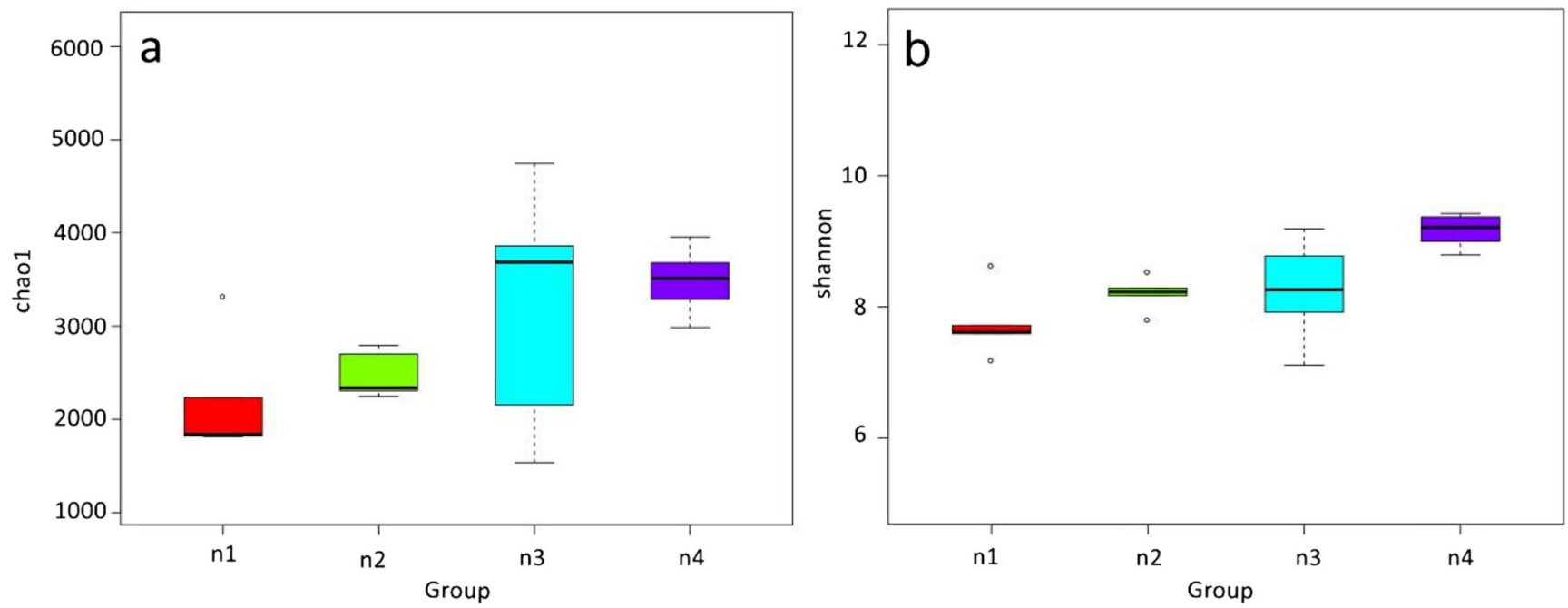

Fig. 3 Bacterial alpha diversity among different environmental types. a chao1. b Shannon index. n1 desert soil, n2 saline-alkali land, n3 saline-alkali wetland, n4 soda lake sediment

Cluster I represented the Pseudomonas group, which was composed of $k 2-4, k 7-8$, and $k 10$. Cluster II included Psychrobacter ( $k 5)$ and Acinetobacter ( $k 9$ ), whereas Hafnia ( $k 1)$ was represented in cluster III, and the Exiguobacterium group $(k 6)$ was present in cluster IV. The extracellular enzyme activities of all 10 isolates were also investigated. All the isolates had alkaline phosphatase and naphthol-AS-BIphosphohydrolase activities. Moreover, almost all the strains (except for $k 5$ ) showed acid phosphatase activity. In addition, multiple types of extracellular enzyme activity were detected in $k 4$ and $k 5$, including that of leucine arylamidase, valine arylamidase, cystine arylamidase, and trypsin in both $k 4$ and $k 5$ and naphthol-AS-BI-phosphohydrolase and N-acetyl- $\beta$ glucosaminidase activities in $k 5$ (Table S3). Additional test on $K 7$ and $K 9$ has shown that those two strains could produce

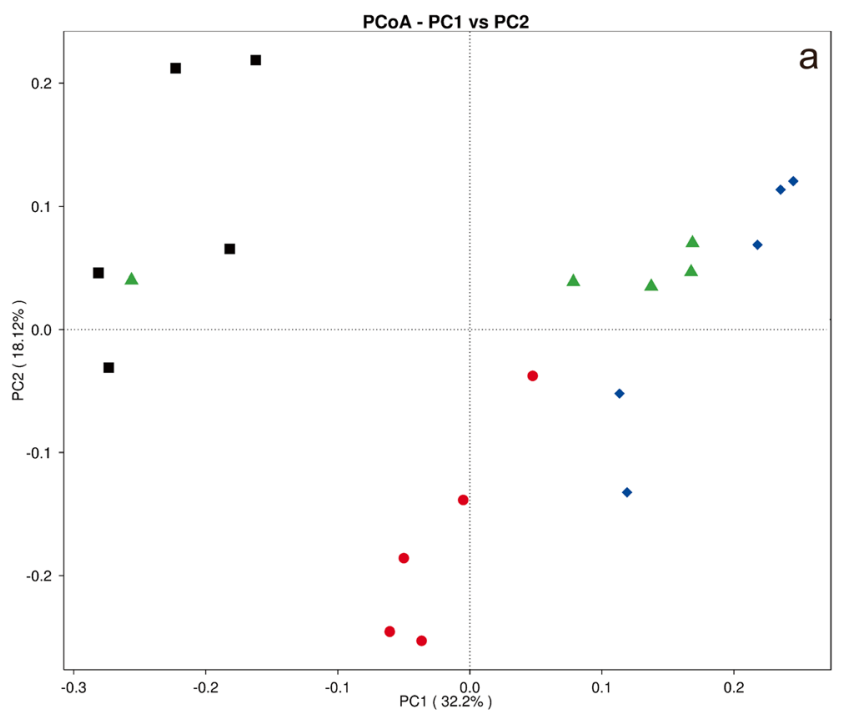

Fig. 4 Principal coordinate analysis (PCoA) based on weighted uniFrac distances (a) and non-metric multidimensional scaling analyses (NMDS) (b) showed a clear differentiation in bacterial communities among the extracellular enzyme under alkaline $(\mathrm{pH} 10)$ and cold $\left(5^{\circ} \mathrm{C}\right)$ condition (Table S4).

\section{Discussion}

In the present study, the most abundant phyla in all samples were Proteobacteria (33.6-39.3\%), Bacteroidetes (7.328.2\%), and Actinobacteria (6.5-21.1\%). This structure was similar to that established in previous studies conducted on the desert soil in the same region, in which Proteobacteria (91\%) was the most abundant phylum, followed by Actinobacteria (7\%) and Firmicutes (2\%) (Su et al. 2011). Similarities were found also concerning the bacterial communities of permafrost layers in Qinghai-Tibet Plateau (Proteobacteria 48.5\%

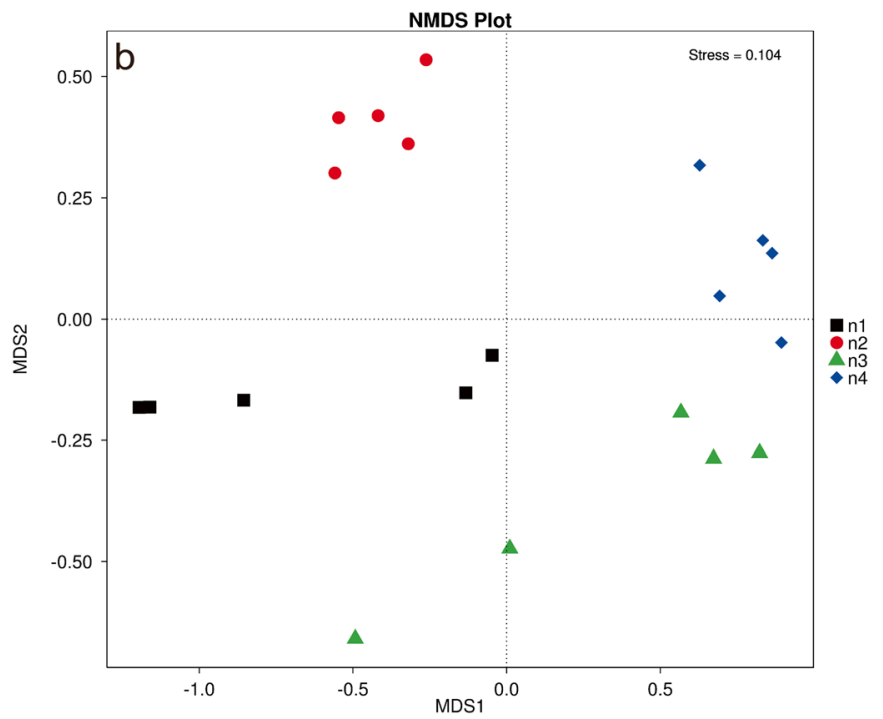

environmental types. $\mathrm{n} 1$ desert soil, $\mathrm{n} 2$ saline-alkali land, $\mathrm{n} 3$ salinealkali wetland, $\mathrm{n} 4$ soda lake sediment 
Table 1 The culturable bacteria isolated from Hoh Xil

\begin{tabular}{lllll}
\hline Isolate no. & Closest related in database & $\begin{array}{l}\text { Identity to closest } \\
\text { related \% }\end{array}$ & $\begin{array}{l}\text { Base pairs } \\
\text { sequenced }\end{array}$ & Accession no. \\
\hline K 1 & Hafnia psychrotolerans & 99.78 & 1382 & MH125153 \\
K & Pseudomonas frederiksbergensis & 99.00 & 1382 & MH125154 \\
K 3 & Pseudomonas mandelii & 99.64 & 1379 & MH125155 \\
K 4 & Pseudomonas syringae & 98.86 & 1228 & MH125156 \\
K 5 & Psychrobacter aquaticus & 99.93 & 1382 & MH125157 \\
K 6 & Exiguobacterium antarcticum & 99.72 & 1404 & MH125158 \\
K 7 & Pseudomonas helmanticensis & 99.35 & 1380 & MH125159 \\
K 8 & Pseudomonas ficuserectae & 99.94 & 1384 & MH125160 \\
K 9 & Acinetobacter lwoffii & 98.70 & 1388 & MH125161 \\
K 10 & Pseudomonas jessenii & 99.00 & 1384 & MH125162 \\
\hline
\end{tabular}

and Actinobacteria 25.4\%) (Su et al. 2011); however, they were different from the bacterial community present in the surface soil (dominated by Actinobacteria) in Ngari (the highest and driest region in the western Tibetan Plateau) (Chu et al. 2016). Moreover, we found that the bacterial community structure identified in our study was exceedingly similar to that of ikaite columns (one of the few permanently cold and alkaline environments on Earth) (Stougaard et al. 2002; Vester et al. 2014). The structures of samples $n 3$ and $n 4$ were similar to those of samples from the Mono Lake (an alkaline lake in the USA) at a depth of $10 \mathrm{~m}$ (Valenzuela-Encinas et al. 2009). We found a set of OTUs (1224) that were present in all samples in the Hoh Xil basin, and the relative abundance of these OTUs did not vary significantly among the samples. Our study reinforces the hypothesis by Baas Becking (1934): "Everything is everywhere, but the environment selects" and was similar with many large-scale soil bacterial community studies that bacteria can disperse globally (Green et al. 2008). Gammaproteobacteria was included, containing several known psychrophiles, such as Psychrobacter sp. and members of the genera Halomonas and Pseudomonas. This finding reveals that the extremely cold environmental on the Qinghai-Tibet Plateau provides ideal conditions for the growth of psychrophilic microorganisms. Meanwhile, at the family level, the bacterial diversity of $\mathrm{n} 1$ differed considerably from those of the other samples. For example, the abundance of Bacillus and Micrococcus, which include many alkaliphilic microorganisms in $n 1$, was significantly lower than that in $\mathrm{n} 3$ and $\mathrm{n} 4$, and there was almost no (only one) Streptomyces OTUs available in $\mathrm{n} 1$, whereas 9, 19, and 22 Streptomyces OTUs were found in $\mathrm{n} 2, \mathrm{n} 3$, and $\mathrm{n} 4$, respectively. The result of $\mathrm{PCOA}$ and NMDS also showed a distinct distribution of $n 1$. To identify the factors that caused the divergence among the bacterial communities in the samples, canonical correspondence analysis (CCA) was performed to evaluate their chemical properties. The $\mathrm{pH}, \mathrm{TC}$, and $\mathrm{NH}^{+4}-\mathrm{N}(P<0.05)$ had the most significant influence on the microbial

Table 2 Growth physiology of culturable bacteria from Hoh Xil

\begin{tabular}{|c|c|c|c|c|c|c|c|c|c|c|c|}
\hline \multirow[t]{2}{*}{ Isolate no. } & \multicolumn{11}{|c|}{ Relative growth ${ }^{\mathrm{a}}$} \\
\hline & pH 6.0 & pH 7.0 & pH 8.0 & pH 9.0 & pH 10.0 & $5^{\circ} \mathrm{C}$ & $10^{\circ} \mathrm{C}$ & $15^{\circ} \mathrm{C}$ & $20^{\circ} \mathrm{C}$ & $30^{\circ} \mathrm{C}$ & $37^{\circ} \mathrm{C}$ \\
\hline K 1 & + & ++ & ++ & ++ & + & + & + & ++ & ++ & ++ & + \\
\hline$K 2$ & + & + & ++ & + & + & ++ & ++ & ++ & ++ & + & - \\
\hline K 3 & + & + & + & ++ & + & + & + & ++ & ++ & ++ & + \\
\hline K 4 & + & ++ & ++ & ++ & + & + & + & + & ++ & ++ & + \\
\hline$K 5$ & + & ++ & ++ & ++ & + & + & ++ & ++ & ++ & ++ & + \\
\hline K 6 & + & ++ & ++ & ++ & + & + & ++ & ++ & ++ & ++ & + \\
\hline$K 7$ & + & + & + & ++ & ++ & + & + & ++ & ++ & ++ & + \\
\hline$K 8$ & + & ++ & ++ & ++ & + & + & ++ & ++ & ++ & + & + \\
\hline$K 9$ & + & + & + & ++ & ++ & ++ & ++ & ++ & ++ & + & - \\
\hline K 10 & + & ++ & ++ & ++ & + & + & + & + & ++ & ++ & + \\
\hline
\end{tabular}

- no growth, + moderate growth, ++ good growth

${ }^{a}$ Relative growth was scored as relative colony size on agar plates 


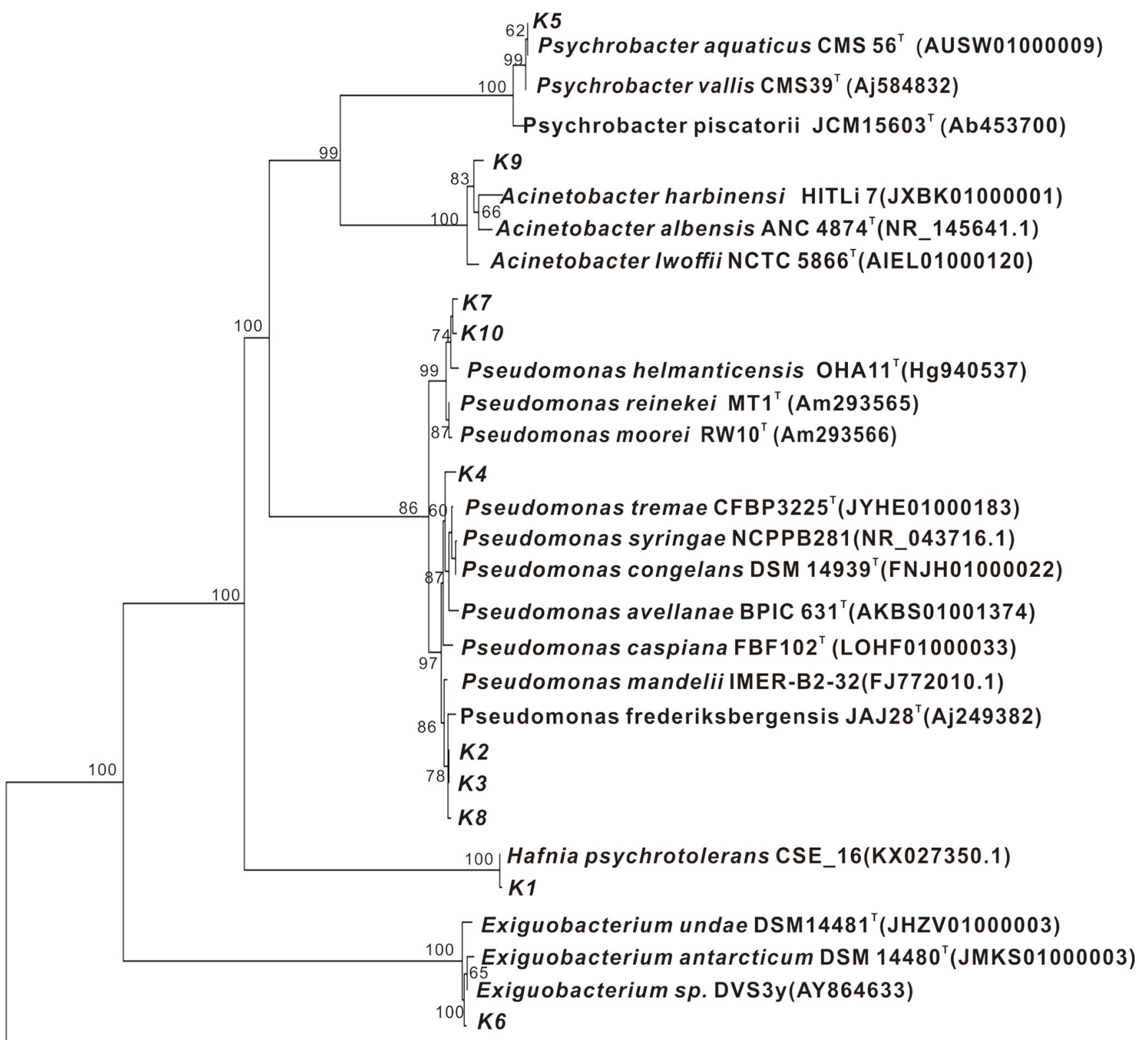

Calditerrivibrio nitroreducens DSM $19672^{\top}$ (AB364234.1)

\subsection{2}

Fig. 5 Phylogenetic analysis based on 16S rDNA sequence. Distances and clustering with the neighbor-joining method were performed by using the software MEGA X. Bootstrap values based on 1000 replications

community structure (Fig. 6), which could explain $36.8 \%$ and $35.5 \%$ and $14.3 \%$ of the total variations.

In the present study, we identified 10 strains of bacteria from 109 isolates, most of which were representatives of Pseudomonas (90.8\%). Our results were considerably different from the findings of former studies, which reported a higher diversity of culturable bacteria, including Bacillus, Gracilibacillus, Halobacillus, Jeotgalibacillus, Paenibacillus, and Psychrobacillus (Su et al. 2011; Sun (bootstrap values of $<50 \%$, not shown) are listed as percentages at the branching points. Bar, 0.02 substitutions per site

et al. 2011; Wang et al. 2017). One important reason for that discrepancy is that we cultured the suspended soil samples at an initial temperature of $5{ }^{\circ} \mathrm{C}$ for the isolation of psychrophiles, while most of the bacteria mentioned above could not grow at such a low temperature. Moreover, our sample was collected from cold and alkaline environments, whereas those in the former studies were collected from the desert. Only Proteobacteria and Firmicutes were detected using culture-dependent methods in all the samples. Another 


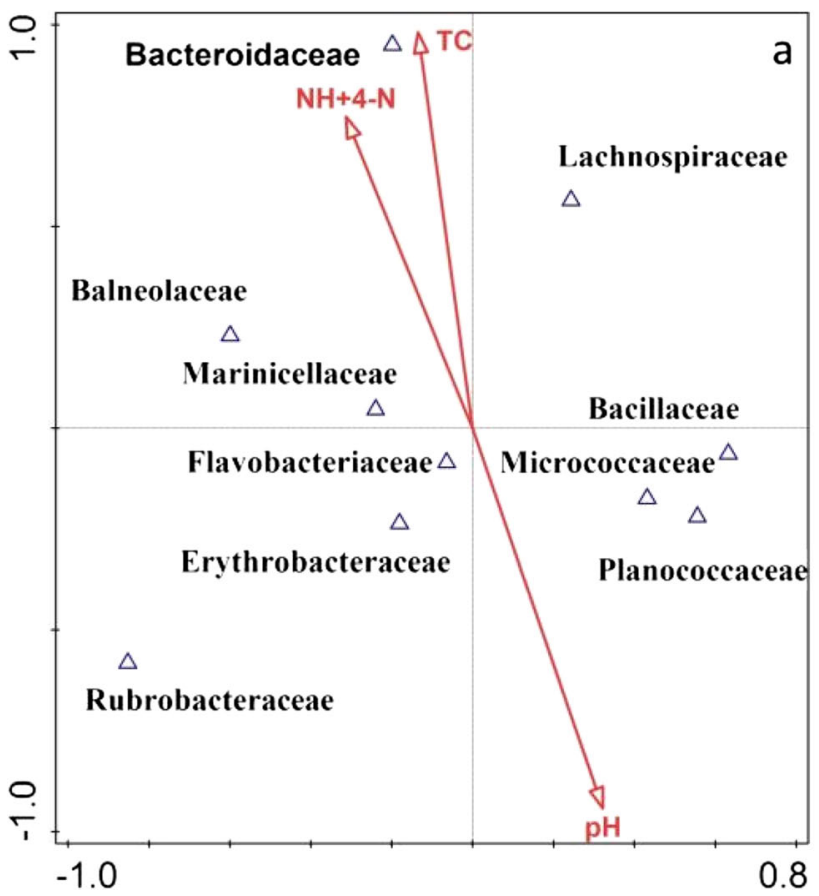

Fig. 6 Canonical correspondence analysis (CCA) of 16S gene data and geochemical parameters. Arrows indicate the direction and magnitude of geochemical parameters associated with bacterial community structures

possible reason is that the culture medium used in our study is the relative eutrophic one; this does not allow to isolate, possibly, many oligotrophic bacteria, as culture-dependent techniques can only disclose some cultivable aerobic and facultative anaerobic bacteria. To contrast, there were six bacterial phyla that have been detected that thought culture-independent method and Proteobacteria, Bacteroidetes, and Actinobacteria were the dominant phyla in all the samples. It was shown that culture-independent methods might provide a powerful strategy to investigate microbes. But, unculturable does not mean can never be cultured; recent studies have shown that previously uncultivable microorganisms could be grown in pure culture if provided with the chemical components from their natural environment (Puspita et al. 2012); thus, a combination of culturedependent and culture-independent methods might be necessary for bacterial community studies.

Nevertheless, all the isolates were able to grow at a low temperature $\left(5^{\circ} \mathrm{C}\right)$, but the optimal growth for the majority occurred at a slightly higher temperature $\left(10-30^{\circ} \mathrm{C}\right)$. They belong to the psychrotolerant microorganisms having a wide temperature range for growth. Only the isolates $\mathrm{k} 2$ and $\mathrm{k} 9 \mathrm{had}$ a good growth at $5{ }^{\circ} \mathrm{C}$, both of which did not grow at $37^{\circ} \mathrm{C}$. Our findings corroborate the former studies that even in the permanent cold environments, the majority of the microflora is psychrotolerant, but not psychrophilic (Simankova et al. 2003). Only the isolates $\mathrm{k} 2$ and $\mathrm{k} 9$ had a good growth at $5{ }^{\circ} \mathrm{C}$, both of which did not grow at $37^{\circ} \mathrm{C}$. The psychrophile $k 2$ was able to grow well at $\mathrm{pH} 8.0$ and $5{ }^{\circ} \mathrm{C}$ and had a high degree of similarity to a psychrotolerant bacterium

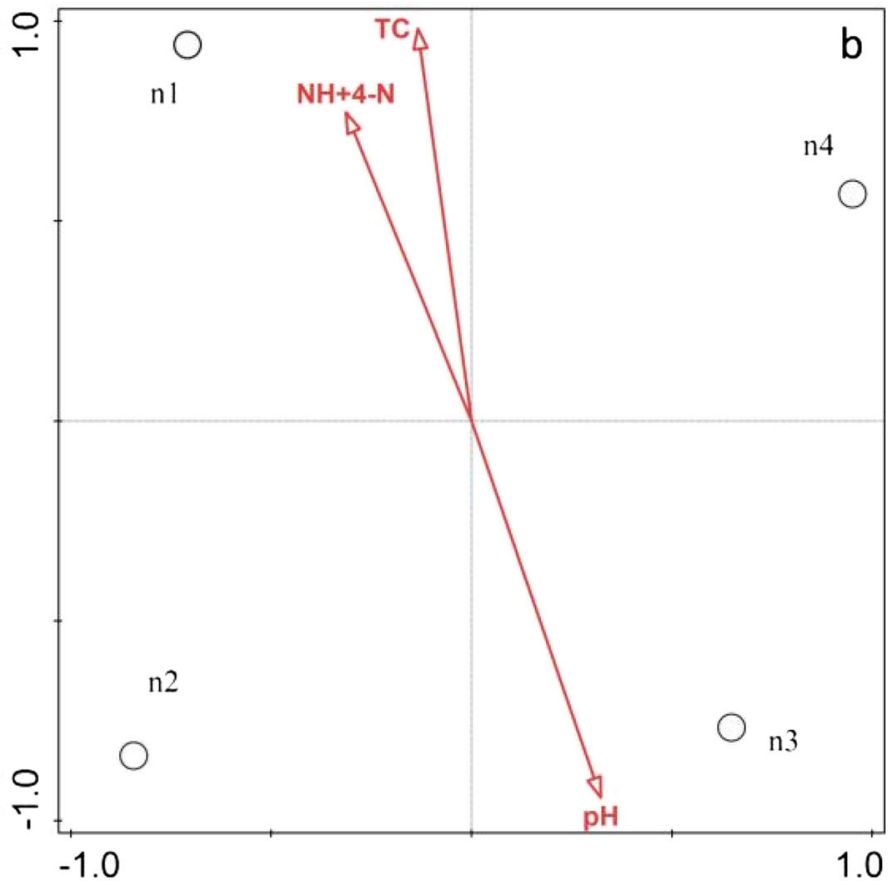

(a) and sample types (b). n1 desert soil, n2 saline-alkali land, n3 salinealkali wetland, $\mathrm{n} 4$ soda lake sediment

(KY405891) isolated from Antarctica. On the other hand, the isolate $k 8$ had a good growth at $\mathrm{pH} 9.0$ and $10^{\circ} \mathrm{C}$, which was similar to the optimal conditions for growth of a bacterium (KU958692) isolated from a soda lake in North America. The isolate $k 9$ grew extremely well under a high value of $\mathrm{pH}$ (pH 10.0) and a low temperature $\left(5^{\circ} \mathrm{C}\right)$, which was similar to the best growth conditions of HF562449, isolated from highmountain lakes in Russia, and JX949550, identified in a glacier in China. In addition, all isolates were able to grow within a wide range of $\mathrm{pH}$ values ( $\mathrm{pH}$ 6.0-10.0), and almost all of them (except for $k 2$ ) grew exceedingly well at $\mathrm{pH} 9.0$. Nonetheless, only the isolates $k 7$ and $k 9$ had a good growth at $\mathrm{pH}$ 10.0. All of the abovementioned isolates are representatives of aerobic bacteria, and the long-term storage in a refrigerator in the presence of oxygen is the most possible reason for the absence of culturable anaerobic bacteria.

\section{Conclusion}

Bacterial communities in cold and alkaline environments of Hoh Xil basin were revealed through Illumina HiSeq 2500, and distinct bacterial communities between different environmental types were found. The bacterial assemblage shifts could be triggered by total carbon, $\mathrm{NH}^{+4}-\mathrm{N}$, and $\mathrm{pH}$ value. The growth of the isolate $k 9$ was optimal at a high $\mathrm{pH}$ value $(\mathrm{pH} 10.0)$ and a low temperature $\left(5^{\circ} \mathrm{C}\right)$ which is a potential psychrophilic and alkaliphilic bacteria with multiple types of extracellular enzyme activity. 
Funding This work was supported by the National Natural Science Foundation of China (No. 31600409), the Open Project of Qinghai Provincial Key Laboratory of Crop Molecular Breeding (2017-ZJ-Y14), the CAS "Light of West China" Program, the National Science and Technology Foundation Project (2015FY110100), and the Strategic Priority Research Program of Chinese Academy of Sciences (XDA2005010406).

\section{Compliance with ethical standards}

Conflict of interest The authors declare that they have no conflict of interest.

Research involving human participants and/or animals This article does not contain any studies with human participants or animals performed by any of the authors.

Informed consent Informed consent is not required in this study.

\section{References}

Caporaso JG et al (2010) QIIME allows analysis of high-throughput community sequencing data. Nat Methods 7:335-336

Caporaso JG et al (2011) Global patterns of 16S rRNA diversity at a depth of millions of sequences per sample. Proc Natl Acad Sci U S A 108: 4516-4522

Cavicchioli R, Charlton T, Ertan H, Mohd OS, Siddiqui KS, Williams TJ (2011) Biotechnological uses of enzymes from psychrophiles. Microb Biotechnol 4:449-460

Chu H, Sun H, Tripathi BM, Adams JM, Huang R, Zhang Y, Shi Y (2016) Bacterial community dissimilarity between the surface and subsurface soils equals horizontal differences over several kilometers in the western Tibetan Plateau. Environ Microbiol 18:15231533

Dixon P (2003) VEGAN, a package of R functions for community ecology. J Veg Sci 14:927-930

Duckworth AW, Grant WD, Jones BE, Steenbergen R (1996) Phylogenetic diversity of soda lake alkaliphiles. FEMS Microbiol Lett 19:181-191

Edgar RC (2010) Search and clustering orders of magnitude faster than BLAST. Bioinformatics 26:2460-2461

Feller G (2013) Psychrophilic enzymes: from folding to function and biotechnology. Scientifica. https://doi.org/10.1155/2013/512840

Fujinami S, Fujisawa M (2010) Industrial application of alkaliphiles and their enzymes - past, present and future. Environ Technol Environ Technol 31:845-856

Green JL, Bohannan BJM, Whitaker RJ (2008) Microbial biogeography: from taxonomy to traits. Science 320:1039-1043

Hall TA (1999) BioEdit: a user-friendly biological sequence alignment editor and analysis program for Windows 95/98/NT. In. Nucl Acids Symp 41:95-98

Horikoshi K (1999) Alkaliphiles: some applications of their products for biotechnology. Microbiol Mol Biol Rev Mmbr 63:735-750

Huse SM, Huber JA, Morrison HG, Sogin ML, Welch DBM (2007) Accuracy and quality of massively parallel DNA pyrosequencing. Genome Biol 8:149-155

Jeanmougin F, Thompson JD, Gouy M, Higgins DG, Gibson TJ (1998) Multiple sequence alignment with Clustal X. Trends Biochem Sci 23:403-405
Kumar S, Stecher G, Li M, Knyaz C, Tamura K (2018) MEGA X: molecular evolutionary genetics analysis across computing platforms. Mol Biol Evol 35:1547-1549

Liu S, Zhao H, Dong S, Nannan AN, Xukun SU, Zhang X (2014) Climate changes in the alpine grassland nature reserves on Qinghai-Tibet Plateau in recent 50 years based on SPEI Index. Ecol Environ Sci 23:1883-1888

Lozupone CA, Knight R (2005) UniFrac: a new phylogenetic method for comparing microbial communities. Appl Environ Microbiol 71: $8228-8235$

Mago T, Salzberg SL (2011) FLASH: fast length adjustment of short reads to improve genome assemblies. Bioinformatics 27:2957-2963

Parks DH, Tyson GW, Hugenholtz P, Beiko RG (2014) STAMP: statistical analysis of taxonomic and functional profiles. Bioinformatics 30 : 3123-3124

Puspita ID, Kamagata Y, Tanaka M, Asano K, Nakatsu CH (2012) Are uncultivated bacteria really uncultivable? Microbes Environ 27: 356-366

Simankova MV, Kotsyurbenko OR, Lueders T, Nozhevnikova AN, Wagner B, Conrad R, Friedrich MW (2003) Isolation and characterization of new strains of methanogens from cold terrestrial habitats. Syst Appl Microbiol 26:312-318

Stackebrandt E, Goodfellow M (1991) Nucleic acid techniques in bacterial systematics. John Wiley and Sons, Hoboken

Stougaard P, Jorgensen F, Johnsen MG, Hansen OC (2002) Microbial diversity in ikaite tufa columns: an alkaline, cold ecological niche in Greenland. Environ Microbiol 4:487-493

Struvay C, Feller G (2012) Optimization to low temperature activity in psychrophilic enzymes. Int J Mol Sci 13:11643-11665

Su j-jZ, Yu-Qin, SUN, Ying, Sun Y (2011) Diversity of culturable and unculturable bacteria in soil samples from Hoh Xil, China. Microbiology China 38:1473-1481

Sun YS, Jing-jing, Liu, Chao, Wei, Yu-zhen, Yu, Li-yan (2011) Isolation and biological characterization of the bacteria from the alkaline soil of Hoh Xil. Microbiol China 38:1473-1481

Tang L, Shen C (1996) Late Cenozoic vegetational history and climatic characteristics of Qinghai-Xizang Plateau. Acta Micropalaeontol Sin 13:321-338

Valenzuela-Encinas C, Neria-González I, Alcántara-Hernández RJ, Estrada-Alvarado I, Fj ZDDLS, Dendooven L, Marsch R (2009) Changes in the bacterial populations of the highly alkaline saline soil of the former Lake Texcoco (Mexico) following flooding. Extremophiles 13:609-621

Vester JK, Glaring MA, Stougaard P (2014) Discovery of novel enzymes with industrial potential from a cold and alkaline environment by a combination of functional metagenomics and culturing. Microb Cell Factories 13(1(2014-05-20) 13):72-72

Wang J et al (2013) Phylogenetic beta diversity in bacterial assemblages across ecosystems: deterministic versus stochastic processes. ISME J 7:1310-1321

Wang XY, Liu GH, Liu B, Chuan-Qing R, Chen Z (2017) Survey of alkaliphilic Bacillus-like resources in Kekexili, Qinghai. Microbiol China 8:1847-1857

Wen X, Yi G, Xu X (2007) Background and precursory seismicities along and surrounding the Kunlun fault before the 8.1, 2001, Kokoxili earthquake, China. J Asian Earth Sci 30:63-72

Zhilina TN, Zavarzin GA (1994) Alkaliphilic anaerobic community at $\mathrm{pH}$ 10. Curr Microbiol 29:109-112

Publisher's note Springer Nature remains neutral with regard to jurisdictional claims in published maps and institutional affiliations. 